\title{
Design of Automatic Assembly Station for Industrial Vehicles Parts
}

\author{
Jozef Jenis $^{1 *}$, Slavomir Hrcek ${ }^{1}$, Frantisek Brumercik ${ }^{1}$ and Ronald Bastovansky ${ }^{1}$ \\ ${ }^{1}$ University of Zilina, Department of Design and Machine Elements, Univerzitna 8215/1, Zilina 010 \\ 26, Slovakia; Email: jozef.jenis@fstroj.uniza.sk, slavomir.hrcek@fstroj.uniza.sk, \\ frantisek.brumercik@fstroj.uniza.sk,ronald.bastovansky@fstroj.uniza.sk
}

\section{*Corresponding Author: Jozef Jenis}

Received: 10 June 2021; Revised: 20 October 2021; Accepted: 3 November 2021; Published: 23 November 2021

\begin{abstract}
Automated production and assembly lines can be considered a crucial factor in accelerating the production processes and achieving the maximum financial savings. In particular, specialized single-purpose machines can significantly reduce production or assembly time. The submitted article presents a design of a single-purpose device that is used for the automated assembly of a roller bush with a screw. These components are then used for construction and agricultural vehicles to attach other components. Naturally, the design of this specific device is more demanding in terms of time consumption, precision, detail and initial investment than similar less complicated all-purpose devices. Nevertheless, single-purpose devices turn out to be a better option in the sense of quality and profit both in the long-term and high-capacity projects, such as automotive industry, agricultural and construction machinery. The best alternative was selected from several proposals using the evaluation method. The assembly machine was designed and optimized using Computer Aided Design systems and Finite Element Method analyses. The resulting equipment was used in practice, where it significantly increased the productivity and production efficiency.
\end{abstract}

Keywords: Roller bushing, assembly, pressing, screw, machinery

\section{Introduction}

Many different design principles must be considered when designing an automated single-purpose system, which differs from traditional automated machine design procedures. High-speed operations pose a number of design challenges, including high accelerations and decelerations, unstable forces and moments during machine operation, and higher loads than traditional machines due to higher cycle repetition [1]. Due to the large volume of output, greater precision and proper positioning of parts is needed, the equipment must not have a negative effect on the environment, 
and, finally, construction materials are a priority. The need for this equipment is based on the effort to minimize weight, complexity, repair, installation, and expense, but it also stems from the need for greater availability, as comparable assembly lines are currently manufactured in Asia, where imports are difficult now; moreover, many of them fall below European standards. The main disadvantage is the fact that they are designed primarily for the assembly of uniform parts, such as screws, rivets, etc. Their introduction to the European market would significantly improve the quality of manufacturing and assembly [2,3].

\section{Description of Automated Assembly Task Component}

The aim is to create an optimal system for automated assembly of housing screws by pressing in accordance with applicable European standards. In order to satisfy the specifications, the system must also be constructed according to the requirements sheet [4]. The designed unit must be versatile and fully self-contained. Switching the computer to a different variant model variant should not take more than 2 hours. Every four hours, the system is turned on for about 30 minutes. The device's annual production would be 9,000,000 bits. One complete assembly must take no more than 3 seconds. A total of 20 pressed assemblies must be produced in one minute. All screws in the assemblies must be tested by taking all screws out of the housing with a force of $10 \mathrm{~N}$. The components, which will be assembled together in the given unit, must be first analysed in order to find the most suitable solution for a given automated assembly system. A practical diagram of the single-purpose machine's operation must be created as well.

\subsection{Roller Bush}

The first component to deal with are roller bushes. There are four different variants (see Fig. 1). All of them are made of EN ISO STN 425301 steel content of class 11 343.1. These parts are rolled into a cylindrical form after being laser-fired from sheet metal with a thickness of $t=1.25 \mathrm{~mm}$. A positioning hole with a diameter of $\phi 3.5 \mathrm{~mm}$ is located in the centre of each housing, immediately in relation to the press. After pressing, the pressing holes on the roller housing would be added. Both sides of each roller have a chamfer of $0.5 \mathrm{~mm}$. Due to the thinness of the housing, a clamping mechanism that circles the entire circumference of the roller sleeve before pressing is needed. This prevents the sheet from bending when being pressed. The individual roller alignments must therefore be designed so that the positioning hole is always aligned with respect to the overhang.

\subsection{Screws}

The system is assembled using seven different kinds of screws (Fig. 1) of different sizes and lengths. The screws are inserted into the system only after the roller bush has been correctly placed. 
Both screw flange diameters have a maximum of $\phi 13.5 \mathrm{~mm}$. Many of the screws have M6 threads. The height of the heads on both screws are $6.5 \mathrm{~mm}$.

\subsection{Final Molded Assemblies}

After positioning the given roller bushing and inserting a special screw, the entire assembly is pressed together in the clamping mechanism using three press heads. The options for arranging the individual assemblies are shown in Fig. 1. Each assembly must be tested after crimping by pressing out the screw with a load force of $\mathrm{F}_{Z}=10 \mathrm{~N}$. If the screw does not come out, it will go to the box. These components are used mainly for transport vehicles, and in particular for large construction and agricultural machinery [5].

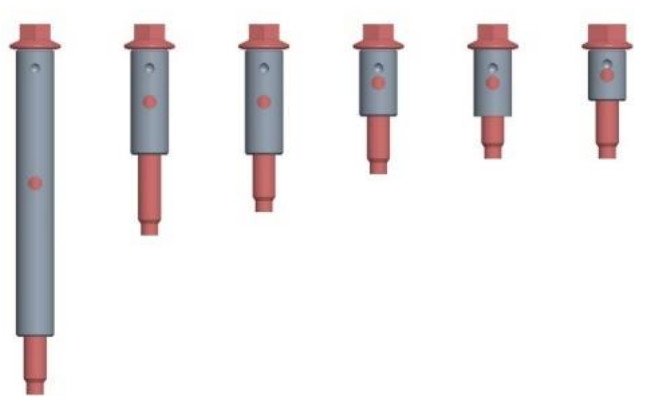

Fig. 1 Assemble of roller bushes and screws. Source: authors

\section{Pressing Assembly Kits}

The assembly is pressed using three pressing heads. The assembly is completed with a ball shape with a diameter of $\phi 3 \mathrm{~mm}$. According to EN ISO STN 41 9312, the punch is made of steel of grade 19 312. The punch is hardened and then tempered. The positioning hole on both roller bushes must face the moulding. Before pressing, a special screw is inserted into the mounted sleeve and the clamping device encircles the roller sleeve around its entire circumference. This prevents the sheet metal to be bent during the pressing process [6]. The positioning hole and the acting of the pushing force are shown in Fig. 2. The rotational resistance of the press heads relative to the positioning hole is $\pm 0.5^{\circ}$. 


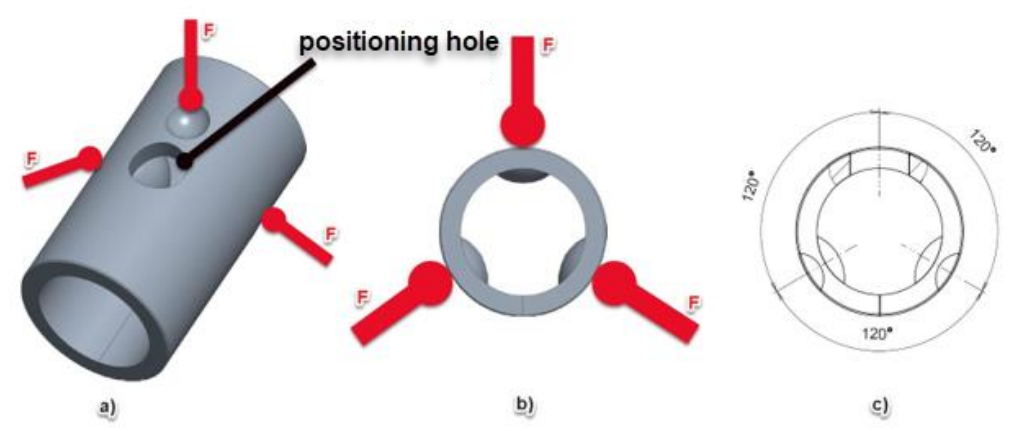

Fig. 2 The effect of pressing force's acting on the roller bush: a) 3D view; b) 2D view; c) roller bush cross section. Source: authors

\section{Automated Operation Sequence}

For a single-purpose assembly system to function properly, the individual technical operations must be well organized and sequenced at the beginning at the beginning of the design process. This is accomplished by a practical scheme, which consists of individual components [7,8] (see Fig. 3). The individual technical activities arranged in order of their execution are as follows:

$\underline{01 . ~ R o l l e r ~ b u s h ~ p o s i t i o n i n g ~-~ t h e ~ o p e r a t o r ~ m a n u a l l y ~ p l a c e s ~ i n d i v i d u a l ~ c y l i n d r i c a l ~ r o l l e r s ~ i n t o ~ t h e ~}$ vibrating hopper of the positioning unit $\left(\mathrm{PZ}_{1}\right)$ and transports them to the next positioning station. After being mounted on multiple positioning devices, the bushes are placed into the interim storage (so that each roller is positioned in a different time range). Once being in the correct position, they are removed. Due to its time-consuming nature, positioning is done in a row. The roller is removed from the assembly line if there is no positioning hole on the roller bush (which may happen) or if it is not well bent $(\mathrm{CH})$.

02. Transporting the roller sleeve from interim storage to the clamping mechanism - the operator transports the roller sleeve from the interim storage to the clamping mechanism. A sensor detects whether or not the screw is present.

03. Screwing the screw into the casing - the operator manually places the individual screws into the positioning system $\left(\mathrm{PZ}_{2}\right)$, where they are aligned in the desired direction. The screw is inserted into a fixed roller bush after it has been turned to the right direction. Once the screw is inserted, the sensor detects its position again.

04. Pressing of the assembly - at this stage, the screw and the roller sleeve are pressed using three press heads. Each of them can be specifically calibrated to the desired extension and force.

05. Checking the assembly's pressing - in the clamping mechanism, the screw is pulled with a force of $10 \mathrm{~N}$ to see if it has been properly pressed.

06. Removing the finished product and packaging - once the part has been pressed, the clamping process is stopped. If the pressing was sufficient, the part is placed in a crate (KLT type) on the 
conveyor $(\mathrm{P})$. If the pressing process stops, the part is removed from the assembly line $(\mathrm{CH})$. Each of the 1,000 pieces serves as a control unit $(\mathrm{K})$.

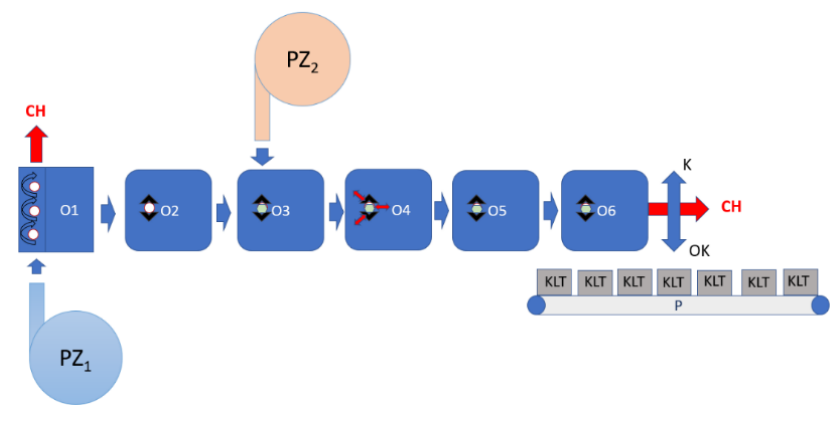

Fig. 3 Functional diagram of automated assembly device. Source: authors

\section{Assembly Stations}

The proposed system is made up of many components, each with its own set of characteristics. The simplest parts of the system are the piece separators, the roller bushes storage station, the rotary table assembly station, conveyor with finished parts, the enclosure, and the device's control system.

\subsection{Separating Station of Individual Components}

At the beginning of the operation, the individual components (roller bushes and screws) need to be sorted out and placed into a specific location. Fig. 4 shows a separating station, where the individual components are arranged using a vibrating hopper.

The roller bushes and screws are moved from the vibrating hopper into the right direction using a vibrating linear feeder. The entire station is supported by a structure composed of ITEM modular profiles. A vibrating refill hopper made by AFAG company is also mounted on the platform to protect the individual components from having to be loaded? into the vibrating hopper at regular intervals $[9,10]$.

\subsection{Cylindrical Positioning Station}

The placement becomes important as the rollers are arranged vertically in the separating station and are deposited in the collector. Three positioning manipulators are located at the positioning station (see Fig. 4) and use rotary gripper heads to lift individual rollers out from their position and place them into the positioning sensors. At this stage, the rotary gripper heads begin to rotate and the sensors search for the positioning hole [11,12]. The individual positioning operators unload the placed rollers into the linear interim storage located behind the rollers in the linear direction until the opening is detected.

The positioning station is placed on the top of a table. The manipulators may fail to locate the positioning hole. It is likely that the curved roller is absent or that the distance created by the curvature is greater than $1 \mathrm{~mm}$. In such a situation, the sensor beam moves across the entire 
diameter of the roller bushing. Such a roller is poorly designed [13]. The positioning manipulator releases the roller sleeve via the overflow hole in the table top, where it falls out following the sheet metal slide to the crate (KLT type), as the PLC program determines that the roller is erroneous in this scenario. After loading, it is emptied by the manipulator.

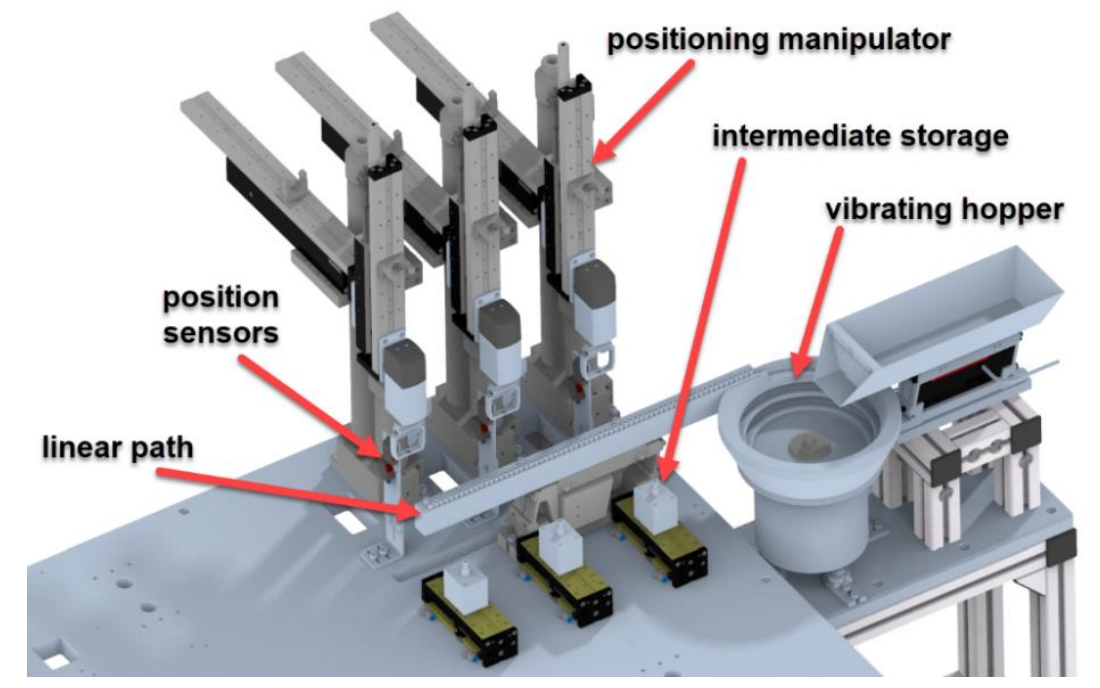

Fig. 4 Positioning station for roller accommodation. Source: authors

\subsection{Assembly Station}

The assembly process begins after the mounted rollers have been placed into the linear pneumatic interim storages (see Fig. 5), which takes place on a rotary table. The entire assembly is completed in four pneumatic chucks: the first one contains a mounted roller, the second one inserts a screw, the third one presses the roller and the screw, and the fourth chuck contains a control station that verifies that the screw with roller bushing is correctly pressed. The entire assembly station is placed on a table made of ITEM profiles $[14,15]$.

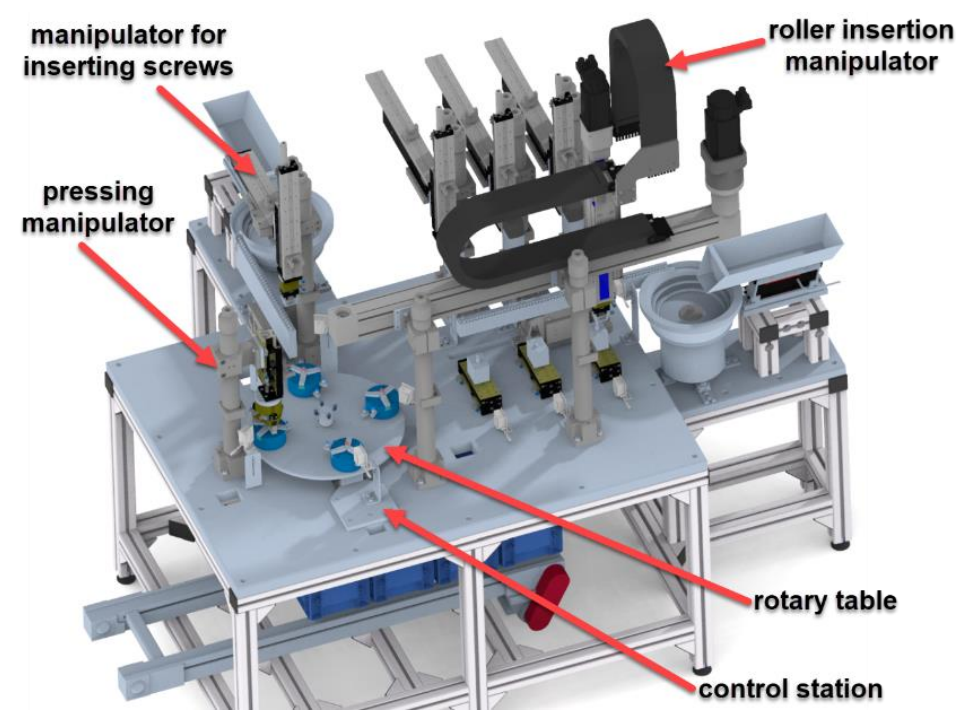

Fig. 5 Assembly station. Source: authors 
For proper setting of the press jaws, it is important to know the internal pressure. This is done using the Finite Element Analysis (FEM) [16,17]. Fig. 6a shows a total deformation of the press jaws. The punch in the $\mathrm{Z}$ axis pushes a maximum of $0.0043 \mathrm{~mm}$ while the pressing force is applied. Fig. $6 \mathrm{~b}$ illustrates the evolution of the internal upset of the punch. The pressing force produces a maximum pressure of $260 \mathrm{MPa}$. Since the yield strength of 19312 steel is approximately $550 \mathrm{MPa}$, the proposed material meets the given requirements.

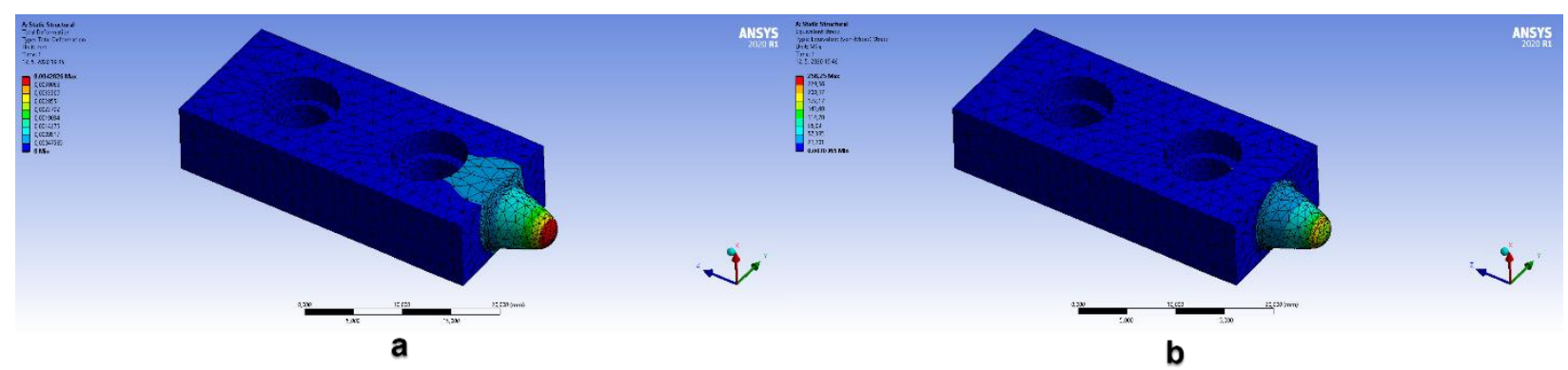

Fig. 6 (a) total deformation of the press jaw; (b) resulting tension on the press jaw. Source: authors

\subsection{Conveyor for Finished Parts}

A conveyor from AFAG company is attached to the device's frame below the assembly station (see Fig. 7). On the conveyor, the completed pressed assemblies are moved from the rotary table into crates - KLT type; (dimensions: 297 x 198 x $147 \mathrm{~mm}$ ). The IL-65 monitor laser sensor from KEYENCE company guarantees the proper location of the crates.

The TBL 320-1400-AR-9 conveyor works at $9 \mathrm{~m} / \mathrm{min} \mathrm{rpm}$. The stepper motor is turned off and the conveyor is stopped after the length of the crate (KLT type) $[18,19]$ was reached before the next crate is loaded. Since the engine is attached to the central control, it has the information about the number of parts in the crate (KLT type). Although the system discards each completed 1,000 parts, the conveyor motor stops. This is a control piece.

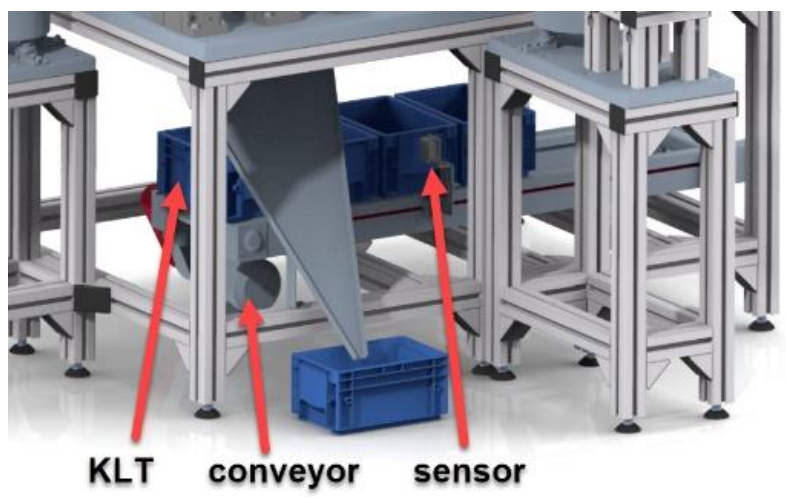

Fig. 7 Press assembly machine. Source: authors

\subsection{Press Assembly Machine}

Fig. 8 shows a professionally assembled press assembly unit. This device can used to assemble seven screws and curved roller bushings. These modules will be used in transportation vehicles in 
the future (especially in agriculture and construction). The entire system meets all specifications given in the specification sheet [20].

The system must also be correctly wired and programmed to avoid accidents or injuries. This must be carried out by experts. The dimensions of the assembly table are 1,500 x 1,100 mm, with the height of 2,100 mm. The dimensions of the entire unit, including the fencing, are 3,700 x 2,600 $\mathrm{mm} \times 2,000 \mathrm{~mm}$.

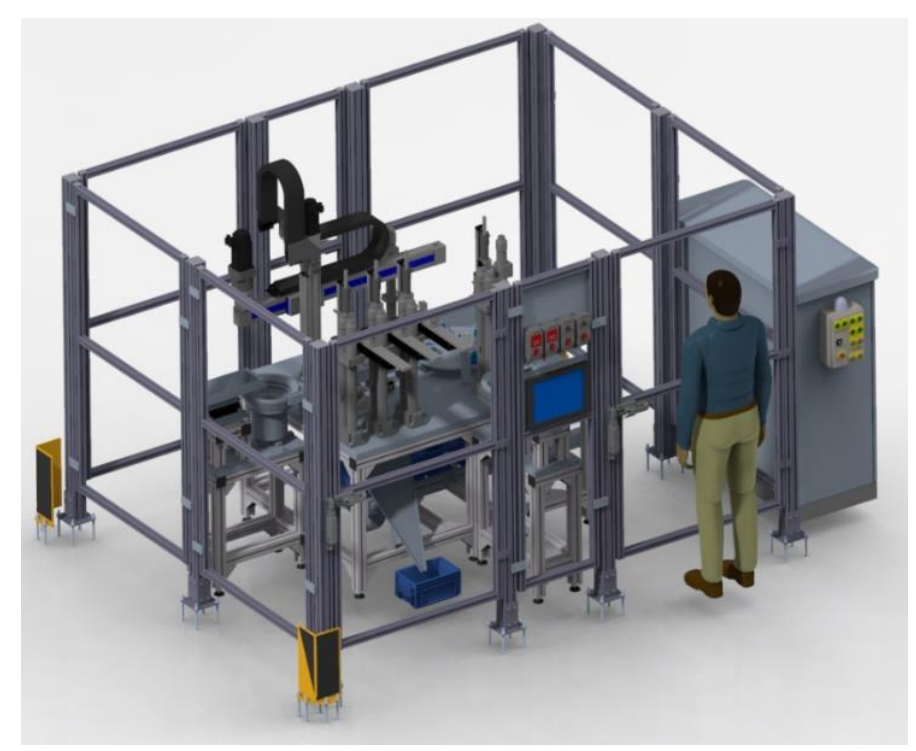

Fig. 8 Press assembly machine. Source: authors

\section{Conclusion}

The goal of this project was to develop and define an optimal system for the automatic assembly of screws and roller bushings by pressing in compliance with the European standards. The device must comply with the specifications outlined in the specification sheet.

The system has been designed to be universal and fully automatic. It takes about an hour to switch the system over to another form of assembly variant. The system is turned on for about 30 minutes every four hours. The device produces about 9,500,000 parts a year. One assembly takes 2.8 seconds, which means that in just one minute, 21 pressed assemblies are formed. By removing all screws from the bushing with a force of $10 \mathrm{~N}$, all screws in the assemblies are tested.

Finite element analysis was performed on the pressing jaws. When using a maximum pressing force of $1.1 \mathrm{kN}$, it was found that the punch in the $\mathrm{Z}$ axis is displaced by a maximum of $0.0043 \mathrm{~mm}$. The overall internal tension of the jaw is $260 \mathrm{MPa}$, which is caused by the pushing force. Since the yield strength of 19312 steel is approximately $550 \mathrm{MPa}$, the proposed material meets the given requirements.

Compared to existing systems, the proposed technology has a number of advantages. The smaller size allows for better positioning in the manufacturing hall and, as a result, more efficient use of space. Another advantage is easy assembly. Fast repair is also a great advantage compared to 
today's computers. Many of the device's critical components are easily replaceable and available. The design of the device can also be a drawback since the system is highly variable, which can result in high costs due to many additional parts and components needed. These benefits and drawbacks, however, are dependent on individual consumer needs. Nevertheless, also in terms of protection, the device under review complies with European norms and standards. The proposed system has been manufactured and applied in practice.

\section{Acknowledgments}

The research is supported by the Cultural and Educational Grant Agency of the Ministry of Education, Science, Research and Sport of the Slovak Republic under the project No. 045ŽU$4 / 2021$.

\section{References}

[1] Gramblicka, S., Kohar, R. \& Madaj, R. (2017). Construction design automatically adjustable mechanism for crane forks. In: 58th International Conference of Machine Design Departments (ICMD 2017), 06-08 September 2017 (pp. 100-103), Czech Univ Life Sci, Fac Engn, Prague, Czech Republic.

[2] Kohar, R., Stopka, M., Weis, P., Spisak, P. \& Steininger, J. (2020). Modular 3D Printer Concept. In: 59th International Conference of Machine Design Departments (ICMD 2018), 11-14 September 2018 (pp. 483-488). Demanovska Dolina, Slovakia. Book Series: Lecture Notes in Mechanical Engineering.

[3] Caco, M., Tribula, R., Scerba, P. \& Kohar, R. (2017). Application of simulation software to optimize construction nodes of ultrasonic welding machines. In: 58th International Conference of Machine Design Departments (ICMD 2017), 06-08 September 2017 (pp. 5659). Czech Univ Life Sci, Fac Engn, Prague, Czech Republic.

[4] Kucera, L., Patin, B., Gajdosik, T., Palencar, R., Palencar, J. \& Ujlaky, M. (2020). Application of Metrological Approaches in the Design of Calibration Equipment for Verification of Float Level Gauges. Book Series: Measurement Science Review, 20(5), 230235. DOI: $10.2478 / \mathrm{msr}-2020-0028$.

[5] Chen, J.Y., Jing, L.M., Hong, T., Liu, H. \& Glowacz, A. (2020). Research on a sliding detection method for an elevator traction wheel based on machine vision. Symmetry. 12 (7) 1158. DOI 10.3390/sym12071158.

[6] Galbavy, M., Pitonak, J. \& Kucera, L. (2014). Powershift Differential Transmission with Three Flows of Power for Hybrid Vehicles. In: 54th International Conference of MachineDesign-Departments, 10-12 September 2013 (pp. 27-33). Hejnice, Czech Republic. Book Series: Modern methods of construction design. DOI: 10.1007/978-3-319-05203-8_4.

[7] Gramblicka, S., Kohar, R., Majchrak, M. \& Vrabec, M. (2020). Contact Analysis of Selected Toothed Contact of the Two-Stage Front Gearbox. In: 59th International Conference of Machine Design Departments (ICMD 2018), 11-14 September 2018 (pp. 263-269). Demanovska Dolina, Slovakia. Book Series: Lecture Notes in Mechanical Engineering.

[8] Kucera, L., Gajdac, I. \& Kamas, P. (2014). Computing and Design of Electric Vehicles. In: 54th International Conference of Machine-Design-Departments, 10-12 September 2013 (pp. 
105-111). Hejnice, Czech Republic. Book Series: Modern methods of construction design. DOI: 10.1007/978-3-319-05203-8_15.

[9] Broncek, J., Drbul, M., Stupavsky, M. \& Radek, N. (2017). The application of new rules of GPS in structural product requirement. In: 58th International Conference of Machine Design Departments (ICMD), 06-08 September 2017 (pp. 50-55). Czech Univ Life Sci, Fac Engn, Prague, Czech Republic.

[10] Kucera, L. \& Gajdosik, T. (2014). The Vibrodiagnostics of Gears. In: 54th International Conference of Machine-Design-Departments, 10-12 September 2013 (pp. 113-118). Hejnice, Czech Republic. Book Series: Modern methods of construction design. DOI: 10.1007/978-3319-05203-8_16.

[11] Sarkan, B., Kuranc, A. \& Kucera, L. (2019). Calculations of exhaust emissions produced by vehicle with petrol engine in urban area. In: 4th International Conference of Computational Methods in Engineering Science (CMES'19), 21-23 November 2019 Article Number: 012023. Kazimierz Dolny, Poland. Book Series: IOP Conference Series-Materials Science and Engineering, 710.

[12] Liptakova, T., Broncek, J., Lovisek, M. \& Lago, J. (2017). Tribological and corrosion properties of Al-brass. In: 33rd Danubia Adria Symposium on Advances in Experimental Mechanics (DAS), 20-23 September 2016 Portoroz, Slovenia. Book Series: Materials todayproceedings, 4(5), 5867-5871.

[13] Drbul, M., Martikan, P., Broncek, J., Litvaj, I. \& Svobodova, J. (2018). Analysis of roughness profile on curved surfaces. Book Series: Innovative technologies in engineering production (ITEP'18), 244. Article Number: 01024. DOI: 10.1051/matecconf/201824401024.

[14] Majchrak, M., Kohar, R., Kajan, J. \& Skyba, R. (2019). 3D Meshing Methods of Ball-Rolling Bearings. In: 13th International Scientific Conference of Young Scientists on Sustainable, Modern and Safe Transport, 29-31 May 2019, Novy Smokovec, Slovakia. Book Series: Transportation Research Procedia, 40, 784-791. DOI: 10.1016/j.trpro.2019.07.111.

[15] Weis, P., Kucera, L., Pechac, P. \& Mocilan, M. (2017). Modal analysis of gearbox housing with applied load. In: 12th International Scientific Conference of Young Scientists on Sustainable, Modern and Safe Transport, 31-Jun 02 May 2017, High Tatras, Slovakia. Book Series: Procedia Engineering, 192, 953-958, DOI: 10.1016/j.proeng.2017.06.164.

[16] Jankejech, P., Fabian, P., Broncek, J. \& Shalapko, Y. (2016). Influence of tempering on mechanical properties of induction bents below 540 degrees C. Book Series: Acta mechanica et automatica, 10(2), 81-86. DOI: 10.1515/ama-2016-0013.

[17] Glowacz, A. (2018). Acoustic-based fault diagnosis of commutator motor. Electronics 7 (11) 299. DOI 10.3390/electronics7110299.

[18] Jambor, M., Kajanek, D., Fintova, S., Broncek, J., Hadzima, B., Guagliano, M. \& Bagherifard, S. (2021). Directing Surface Functions by Inducing Ordered and Irregular Morphologies at Single and Two-Tiered Length Scales. Book Series: Advanced Engineering Materials, 23(2). Article Number: 2001057. DOI: 10.1002/adem.202001057.

[19] Orman, L.J., Radek, N. \& Broncek, J. (2018). Sintered Mesh Layers for the Production of Efficient Phase - Change Heat Exchangers. Book Series: Terotechnology, 5, 189-193. DOI: 10.21741/9781945291814-33.

[20] Glowacz, A. (2019). Acoustic fault analysis of three commutator motors. Mechanical Systems and Signal Processing. 133 106226. DOI 10.1016/j.ymssp.2019.07.007. 